ORIGINAL ARTICLE

\title{
The Role of Sleep Quality and Mental Health in Cardiovascular Disease
}

ROYA VAZIRI-HARAMI, M.D ${ }^{1}$; PEGAH SEIF, MD ${ }^{2 *}$; ALI KHERADMAND, MD ${ }^{3}$; SAHARNAZ VAZIRI-HARAMI, MD 4

${ }^{1}$ Department of Psychiatry and Behavioral Neuroscience Research Center, Imam Hossein Hospital, Shahid Beheshti University of Medical Sciences, Tehran, Iran. Roya.vaziriharami@sbmu.ac.ir

${ }^{2}$ Resident of Psychiatry, Faculty of Medicine, Shahid Beheshti University of Medical Sciences, Tehran, Iran. pegahsafe@gmail.com

${ }^{3}$ Assistant professor of psychiatry, Taleghani Hospital Research Development Committee, Shahid Beheshti University of Medical Sciences, Tehran,Iran.ali_kheradmand@yahoo.com

${ }^{4}$ Medical Student, Faculty of Medicine Islamic Azad Tehran University of Medical Sciences, Tehran, Iran. saharnazvazirih99@gmail.com Corresponding author: Pegah Seif, M.D.pegahsafe@gmail.com, Address: Imam Hossein Medical Center, Tehran, Iran. Telefax: $+982177551023$

\begin{abstract}
Objectives: Cardiovascular diseases (CVDs) may accompany other diseases. Of which can name sleep disorders and also other psychiatric disorders.

Aim: In current study we evaluate the concomitant mental health disorders and the sleep quality among the acute myocardial infarction (AMI) and acute coronary syndrome (ACS) patients.

Method:180 cases were selected through random sampling. 90 of the cases were hospitalized because of acute myocardial AMI and 90 patients were admitted with the diagnosis of ACS. Demographic, GHQ-28 and PSQI questionnaire was applied to evaluate the demographic features, psychological wellbeing and sleep quality subsequently.

Results: $57.8 \%$ of cases were women $42.2 \%$ were men. The age range was $27-75$ years old and the mean age was $49.93 \pm 11.73$ years old. $87.8 \%$ of the patients were married and rest were single. The mean score for the GHQ-28 questionnaire was22.43 \pm 10.99 in patients with angina and $24.93 \pm 10.19$ in AMI patients. $38.8 \%$ of ACS patients and $50 \%$ of AMI patients didn't feel well psychologically. The mean score for sleep quality in ACS patients was $3.08 \pm 3.6$ and $4.06 \pm 3.8$ in AMI patients. $32.3 \%$ of ACS cases and $24.4 \%$ of AMI cases had troubles in sleeping.

Conclusion: The mental health disorders prevail in AMI and ACS patients. Furthermore, the poor sleep quality was correlated with mental health disorders.

Keywords: Sleep Wake Disorders, Mental Health, Acute Coronary Syndrome, Myocardial Infarction
\end{abstract}

\section{INTRODUCTION:}

Sleep has fundamental role in keep our nervous functioning and keep us survive (1). We spend about one-third of our life sleeping. During sleep various neural pathways from cortex to the heart will get involve $(2,3)$. Sufficient duration, depth and continuity is essential for maintain attention and cognitive performance and to prevent harms to physiological and psychological health (4). Our body biological functions alters when we are sleeping. Hormone's secretion, immune function and many other systems acts different during the sleep than the awake time. Short sleep duration or circadian desynchrony may cause various problems such as weight gain (5), obesity (6), diabetes (7). Hence one of the important systems regulations during the sleep is cardiovascular regulation. Heart rate and arterial blood pressure is modifying while we are asleep [8]. Sleep problems may cause cardiovascular disorders, hypertension, angina, Ml and stroke (9).

The consequences of mental health on cardiovascular diseases are proven form the childhood to the adulthood (10). For instance, the researches have shown the indirect correlation between the maternal depression and heart disease in children (11). Likewise, the psychosocial stress, chronic anger and hostility precipitate progression of coronary artery diseases (12). The exact pathophysiological correlation between many psychological distress and other related factors and atherogenesis remain vague. Nevertheless, it has been proposed that chronic stress cause activation in sympathetic nervous system. The sympathetic nervous system will have an effect on pulse rate, blood pressure and consequently the cardiac work. These factors per se will increase the likelihood of the cardiac arrhythmia and cardiovascular reactivity (13).

In this study we decided to appraise the preponderance of mental health disorders and sleep quality amid the group of the patients hospitalized for myocardial infarction or unstable/ stable angina pectoris.

\section{METHODS}

In this survey we analyzed the patients admitted to CCU ward, in Imam Hussein Hospital because of acute myocardial infarction (AMI) and acute coronary syndrome (ACS) during the year 2018 in Tehran, Iran. 180 cases were selected through random sampling according to statistics formulas included in $90 \mathrm{AMI}$ patients and 90 patients hospitalized because of ACS. All the study process were thoroughly explained and confidentiality was guaranteed for all the data driven and all the information obtained from this research will not improperly divulged.

Assessment tools: Demographic questionnaire: Was used to identify the age, sex and marital status of all the participants.

General Health Questionnaire-28 (GHQ-28): Is a selfreport test for detecting mental health problems during the month before the assessment take place (14). This test is consisted of four subdivisions cover different symptoms respectively: somatic symptoms, anxiety and insomnia, 
social dysfunction and severe depression. Every part is consisted of 7 questions which score from 0 to 3 is given to A-D options; respectively. The score higher than 22 shows psychiatric disorders, and those who scores below 22 are normal (15). This test is validated in Persian (16). We used this questionnaire to evaluate the psychological well-being of the cases in this study.

The Pittsburgh Sleep Quality Index (PSQI): Is a selfadministered questionnaire to estimate the sleep quality of the individuals over the prior 4 weeks (17). This test is available in different languages $(18,19)$ and Persian $(20)$ and this make it a suitable tool to analyze the sleep disorders in clinical and non- clinical settings. This assessment tool consisted of 19 items in seven part, scores range from 0 to 3 which investigate the subjective sleep quality, sleep latency, habitual sleep efficiency, total sleep time, sleep perturbations, use medication to sleep and daytime dysfunction. The points higher than 5 shows the poor sleep quality (17).

Statistical analysis: All the data analyzed by SPSS version 16. The qualitative data were described by using frequency and percentage. The relationship between the mental health and sleep quality was assessed by the Chisquare Test. In all the tests the p-value $<0.05$ was considered statistically significant.

Ethical Considerations: It was conducted based on Helsinki Declaration.

\section{RESULTS}

We evaluated 180 patients of which 104 cases $(57.8 \%)$ were women and 76 patients $(42.2 \%)$ were men. The participants were between 27 to 75 years old and the mean age of them was $49.93 \pm 11.73$ years old. $138(87.8 \%)$ of the patients were married and $22(12.2 \%)$ were single at the time of this study. The result of mental health amid men and women was analyzed and showed in table 1.

Among the group of the unstable/ stable angina patients the mean score for the GHQ-28 questionnaire was $22.43 \pm 10.99$ which indicates the mental health disorder in this group of the cases. Of total 90 ACS cases in this group 35 cases $(38.8 \%)$ didn't feel well psychologically whereas 55 patients $(62.2 \%)$ scored higher than the cutoff point and their mental health were optimal. In the group of AMl patients the mean score for the GHQ-28 questionnaire was 24.93+10.19. $45(50 \%)$ of the participants gained an optimal score in this test on the other side $45(50 \%)$ of the cases suffered from psychiatric disorders. The psychological well-being was the same between both sexes ( $p$-value $=0.4)$, although the difference between the single and married cases was apparent. $97.5 \%$ of the married cases and $2.5 \%$ of the single cases experienced psychological disorders ( $p$-value=0.01).

In assessing the sleep quality amid the ACS patients, the test score of $3.08+3.6$ on average. 20 cases out of the total 90 cases $(32.3 \%)$ in this group had poor sleep quality and the rest of them $(77.7 \%)$ had a good sleep quality. While on the contrary among the AMl patients, the mean score on this test was $4.06+3.8$. $26(24.4 \%)$ of the individuals having had troubles in sleeping and $64(75.6 \%)$ slept well. The results also showed the frequency of sleep disorders were not statistically significant among men and women. 28 women cases $(66.7 \%)$ and 14 men $(33.7 \%)$ had sleep disorders ( $p$-value $=0.34$ ). The sleep quality was not the same in married and single cases. All the cases with sleep problems were married and sleep quality was optimal in single participants ( $p$-value $=0.04)$.

In comparing sleep quality and psychological wellbeing, it was shown that in $35(38.9 \%)$ ACS cases with sleep problems psychiatric disorders also existed ( $p$ value $<0.001$ ). (Table 2 and 3 )

Furthermore $50 \%$ of the Ml cases with sleep problems had impaired mental well-being as well ( $p$ value $<0.001)$. This indicated the statistically meaningful correlation between the sleep quality and mental health. (Table 4 and table 5)

Through this investigation we also evaluate the prevalence of mental health in each subgroup of the GHQ28 questionnaire. The most prevalent GHQ-28 questionnaire subtypes in our study population were the anxiety disorders 50 (55.6\%) and social dysfunction (47.8\%). (Table 6)

\section{DISCUSSION}

The current study was done over the AMI patients and ACS patients. By using PSQI questionnaire for sleep quality evaluation it was concluded that $32.3 \%$ of unstable/stable patients and $24.4 \%$ of Ml patients had sleep problems. In general population the prevalence of insomnia was reported in about 6 to $15 \%$ (21) whereas the insomnia is not a rare condition following stroke (22). Furthermore, insomnia is already present before the myocardial infarction happens in many patients (23). According to the prior systematic reviews the prevalence of insomnia in AMI patients was about $38.2 \%$ with female predominance (24) although we couldn't find such relevancy with women as the prevalence of overall sleep disorders were not different between the two sex. Additionally, the shorter sleep duration was named also as an important factor in developing cardiovascular events in some studies (25). As it was noted in a meta-analysis, the sleep duration less than 7 hours per night may increase the ACS recurrence rate or even death in half of the cases during the following year of the investigation. Besides more than half of ACS patients in this survey slept less than 7 hours at night in this report (26). In another systemic review which analyzed the sleep structure as well, 26 studies were in investigating the sleep quality among ACS cases. 18 studies were done immediately after occurring ACS. They reported the shorter slow wave sleep duration and also a decrease in REM sleep. moreover, they reported an increase in N1 and N2 sleep stage right after the ACS. Although these changes would return to normal in the next months (27). There were also precious studies for finding the correlation between sleep disturbances, the mortality risk and the risk for other cardiovascular events. Of which, one study was done over the 2,246 first time acute myocardial infarction Swedish patients. In this evaluation they used Karolina Sleep Questionnaire to analyze the sleep quality. One third of the women in addition to more than $20 \%$ of men had sleep problems. It was shown that those women with poor sleep quality would have higher risk for developing long term cardiovascular events such as AMI, stroke or heart failure. But any correlation was found in higher fatality rate among them. Their findings showed a direct relationship in men 
although. As the sleep problems were increased among them the case fatality was augment also in the same direction. The cardiovascular outcome could not be predicted among the men cases in this study (28). The appraisal of AMI patients in our study didn't showed us any difference, in sleep quality, between the men and women.

The association between the educational level and sleep quality was shown in 717 coronary artery diseases cases. As it was deduced from this report the female with the lower education level had worse sleep quality. But the same correlation didn't exist among the men (29).

The high concordance of mental health disorders in cardiovascular patients was mentioned in several resources and the importance of the psychological wellbeing in these patients is being emphasized (30). The presence of depression (31), anxiety (32), stress (33) and other mental health disorders is illustrated in developing the cardiovascular diseases.

One cohort study was conducted over the patients admitted for the ACS events in a 3 months period after their hospitalization. In total 88 patients were included in this survey about $21(23.9 \%)$ had already suffered from major depression disorder (MDD) symptoms at the time of admission. Of this number $14(66.7 \%)$ have had previous MDD episodes and the rest were new cases of MDD. They concluded that the incident depression may predict the CAD severity not the recurrent depression (34). The other reports are also in favor of this concept that the depressive symptoms at the time of patient's admission is much more significant than before the hospitalization $(35,36)$. We assessed the comorbid psychiatric disorders in our study population by the means of GHQ-28 questionnaire during the previous month ended to their admission. The other papers had reported depression in post Ml patients is a strong predictor of poor prognosis and the major adverse cardiovascular events among these patients will increase 2-fold to 2.7 -fold $(37,38)$.

In another meta-analysis over 39038 patients with ACS across different countries amid the MI, ACS and UA patients, it was demonstrated that the anxiety over these population was ranged from $9.1 \%$ to $58.2 \%$. Their findings showed that the mortality risk in ACS patients who were also suffered from anxiety at the time of hospitalization was $21 \%$. The importance of anxiety disorders and cardiac disorders is also highlighted in different other papers. As it was demonstrated in another meta-analysis the ACS patients with anxiety have the same mortality rate of $21 \%$ and they have a $47 \%$ higher risk for developing major adverse cardiovascular events compared with the ACS without anxiety. But in the case of presence concurrent depression and anxiety depression is more important to predict the prognosis of cardiovascular events than anxiety (39).

According to our findings $38.8 \%$ of ACS patients and $50 \%$ of the AMI patients had mental health troubles and the more prevalent disorder $(55.6 \%)$ in these group with mental disorder was the anxiety disorders.

Limitations: The greater number of participants can predict the results more accurately. The role of the educational level in sleep quality and mental health is considerable and which has to be considered also in this assessment. It seems better to evaluate each type of sleep disorder separately among these two groups to find more precise linkage. The GHQ-28 sub scores would be different in each of the groups and should be reported more in detail.

Conflict of interest: We declare no conflict of interest. Acknowledgments: None

\section{REFERENCES:}

1. What is Sleep and Why is It Important? I American Sleep Association [Internet]. [cited 2020 Nov 20]. Available from: https://www.sleepassociation.org/about-sleep/what-is-sleep/

2. Saper CB, Scammell TE, Lu J. Hypothalamic regulation of sleep and circadian rhythms. Nature. 2005 Oct 27;437(7063):1257-63. doi: 10.1038/nature04284. PMID: 16251950.20842084208420842084

3. Tononi G, Cirelli C. Sleep function and synaptic homeostasis. Sleep Med Rev. 2006 Feb;10(1):49-62. doi: 10.1016/j.smrv.2005.05.002. Epub 2005 Dec 22. PMID: 16376591.

4. Buxton OM, Cain SW, O'Connor SP, Porter JH, Duffy JF, Wang W, Czeisler CA, Shea SA. Adverse metabolic consequences in humans of prolonged sleep restriction combined with circadian disruption. Sci Transl Med. 2012 Apr 11;4(129):129ra43. doi: 10.1126/scitranslmed.3003200. PMID: 22496545; PMCID: PMC3678519.

5. Arble DM, Bass J, Laposky AD, Vitaterna MH, Turek FW. Circadian timing of food intake contributes to weight gain Obesity (Silver Spring). 2009 Nov;17(11):2100-2. doi: 10.1038/oby.2009.264. Epub 2009 Sep 3. PMID: 19730426; PMCID: PMC3499064.

6. Kobayashi D, Takahashi O, Deshpande GA, Shimbo T, Fukui T. Association between weight gain, obesity, and sleep duration: a large-scale 3-year cohort study. Sleep Breath. 2012 Sep;16(3):829-33. doi: 10.1007/s11325-011-0583-0. Epub 2011 Sep 3. PMID: 21892668.

7. Chao CY, Wu JS, Yang YC, Shih CC, Wang RH, Lu FH Chang CJ. Sleep duration is a potential risk factor for newly diagnosed type 2 diabetes mellitus. Metabolism. 2011 Jun;60(6):799-804. doi: 10.1016/j.metabol.2010.07.031. Epub 2010 Sep 16. PMID: 20846701.

8. Kendzerska T, Mollayeva T, Gershon AS, Leung RS, Hawker G, Tomlinson G. Untreated obstructive sleep apnea and the risk for serious long-term adverse outcomes: a systematic review. Sleep Med Rev. 2014 Feb;18(1):49-59. doi: 10.1016/j.smrv.2013.01.003. Epub 2013 May 1. PMID: 23642349

9. Altman NG, Izci-Balserak B, Schopfer E, Jackson N, Rattanaumpawan P, Gehrman PR, Patel NP, Grandner MA. Sleep duration versus sleep insufficiency as predictors of cardiometabolic health outcomes. Sleep Med. 2012 Dec;13(10):1261-70. doi: 10.1016/j.sleep.2012.08.005. Epub 2012 Nov 8. PMID: 23141932; PMCID: PMC3527631.

10. Danese A, Moffitt TE, Harrington H, Milne BJ, Polanczyk G, Pariante CM, Poulton R, Caspi A. Adverse childhood experiences and adult risk factors for age-related disease: depression, inflammation, and clustering of metabolic risk markers. Arch Pediatr Adolesc Med. 2009 Dec;163(12):113543. doi: 10.1001/archpediatrics.2009.214. PMID: 19996051; PMCID: PMC3560401.

11. Surkan PJ, Kennedy CE, Hurley KM, Black MM. Maternal depression and early childhood growth in developing countries: systematic review and meta-analysis [published correction appears in Bull World Health Organ. 2011 Sep 1;89(9):631]. Bull World Health Organ. 2011;89(8):608-615. doi:10.2471/BLT.11.088187

12. Goodwin RD, Davidson KW, Keyes K. Mental disorders and cardiovascular disease among adults in the United States. J Psychiatr Res. 2009 Jan;43(3):239-46. doi: 
10.1016/j.jpsychires.2008.05.006. Epub 2008 Jul 9. PMID: 18614179; PMCID: PMC3340909.

13. Vella EJ, Friedman BH. Hostility and anger in: cardiovascular reactivity and recovery to mental arithmetic stress. Int $J$ Psychophysiol.

2009;72(3):253-259. doi:10.1016/j.jpsycho.2009.01.003

14. Goldberg D, Williams P. A user's guide to the general health questionnaire. London: Nfer-Nelson; 1991.

15. Goldberg DP, Hillier VF. A scaled version of the general health questionnaire. Psychol Med. 1979;9(1):139-45.

16. Noorbala $A$, Mohammad $K$. The validation of general health questionnaire-28 as a psychiatric screening tool. Hakim Res J. 2009;11:47-53

17. Buysse DJ, Reynolds CF 3rd, Monk TH, Berman SR, Kupfer DJ. The Pittsburgh Sleep Quality Index: a new instrument for psychiatric practice and research. Psychiatry Res. 1989 May;28(2):193-213. doi: 10.1016/0165-1781(89)90047-4. PMID: 2748771 .

18. Ait-Aoudia M., Levy P.P., Bui E., Insana S., de Fouchier C., Germain A., Jehel L. Validation of the French version of the Pittsburgh Sleep Quality Index addendum for posttraumatic stress disorder. Eur. J. Psychotraumatol. 2013;4:19298. doi: 10.3402/ejpt.v4i0.19298

19. Manzar MD, Moiz JA, Zannat W, Spence DW, Pandi-Perumal SR; Ahmed S. BaHammam, Hussain ME. Validity of the Pittsburgh Sleep Quality Index in Indian University Students. Oman Med J. 2015 May;30(3):193-202. doi: 10.5001/omj.2015.41. PMID: 26171126; PMCID: PMC4459159.

20. Chehri A, Kiamanesh A, Ahadi H, Khazaie H. Psychometric Properties of the Persian Version of Sleep Hygiene Index in the General Population. Iran J Psychiatry Behav Sci. 2016;10(3):e5268. Published 2016 Aug 7. doi:10.17795/ijpbs5268

21. Riemann D, Baglioni C, Bassetti C, Bjorvatn B, Dolenc Groselj L, Ellis JG et al. European guideline for the diagnosis and treatment of insomnia. J Sleep Res. 2017 Dec;26(6):675700. doi: 10.1111/jsr.12594. Epub 2017 Sep 5. PMID: 28875581.

22. Pérez-Carbonell L, Bashir S. Narrative review of sleep and stroke. J Thorac Dis. 2020;12(Suppl 2):S176-S190. doi:10.21037/jtd-cus-2020-002

23. Leppävuori A, Pohjasvaara T, Vataja R, Kaste M, Erkinjuntti T. Insomnia in ischemic stroke patients. Cerebrovasc Dis. 2002;14(2):90-7. doi: 10.1159/000064737. PMID: 12187012.

24. Baylan S, Griffiths S, Grant N, Broomfield NM, Evans JJ, Gardani M. Incidence and prevalence of post-stroke insomnia: A systematic review and meta-analysis. Sleep Med Rev. 2020 Feb;49:101222. doi: 10.1016/j.smrv.2019.101222. Epub 2019 Oct 28. PMID: 31739180.

25. Eguchi K, Hoshide S, Ishikawa S, Shimada K, Kario K. Short sleep duration is an independent predictor of stroke events in elderly hypertensive patients. J Am Soc Hypertens. 2010 Sep-Oct;4(5):255-62. doi: 10.1016/j.jash.2010.09.001. PMID: 20940066

26. Madsen MT, Huang C, Zangger G, Zwisler ADO, Gögenur I. Sleep Disturbances in Patients With Coronary Heart Disease: A Systematic Review. J Clin Sleep Med. 2019;15(3):489-504. Published 2019 Mar 15. doi:10.5664/jcsm.7684

27. Clark A, Lange T, Hallqvist J, Jennum P, Rod NH. Sleep impairment and prognosis of acute myocardial infarction: a prospective cohort study. Sleep. 2014;37(5):851-858. Published 2014 May 1. doi:10.5665/sleep.3646
28. Ohayon MM. Prévalence et comorbidité des troubles du sommeil dans la population générale [Prevalence and comorbidity of sleep disorders in general population]. Rev Prat. 2007 Sep 30;57(14):1521-8. French. PMID: 18018450.

29. Assari S, Moghani Lankarani M, Kazemi Saleh D, Ahmadi K. Gender modifies the effects of education and income on sleep quality of the patients with coronary artery disease. Int Cardiovasc Res J. 2013 Dec;7(4):141-6. Epub 2013 Dec 1. PMID: 24757639; PMCID: PMC3987449.

30. Kubzansky LD, Huffman JC, Boehm JK, Hernandez R, Kim ES, Koga HK, Feig EH, Lloyd-Jones DM, Seligman MEP, Labarthe DR. Reprint of: Positive Psychological Well-Being and Cardiovascular Disease: JACC Health Promotion Series. J Am Coll Cardiol. 2018 Dec 11;72(23 Pt B):3012-3026. doi: 10.1016/j.jacc.2018.10.023. PMID: 30522634.

31. Gan $Y$, Gong $Y$, Tong $X$, Sun $H$, Cong $Y$, Dong $X$, Wang $Y, X u$ $X$, Yin X, Deng J, Li L, Cao S, Lu Z. Depression and the risk of coronary heart disease: a meta-analysis of prospective cohort studies. BMC Psychiatry. 2014 Dec 24;14:371. doi: 10.1186/s12888-014-0371-z. PMID: 25540022; PMCID: PMC4336481.

32. Batelaan NM, Seldenrijk A, Bot M, van Balkom AJ, Penninx BW. Anxiety and new onset of cardiovascular disease: critical review and meta-analysis. $\mathrm{Br} J$ Psychiatry. 2016 Mar;208(3):223-31. doi: 10.1192/bjp.bp.114.156554. PMID: 26932485.

33. M. Kivimaki. Psychosocial factors in etiology and prognosis of specific diseases and disorders: cardiovascular diseases. M. Kivimaki, D.G. Batty, I. Kawachi, A.Steptoe (Eds.), Handbook of Psychosocial Epidemiology, Routledge, New York, NY. 2018, pp. 247-262

34. Goodman J, Shimbo D, Haas DC, Davidson KW, Rieckmann $\mathrm{N}$. Incident and recurrent major depressive disorder and coronary artery disease severity in acute coronary syndrome patients. J Psychiatr Res. 2008;42(8):670-675. doi:10.1016/j.jpsychires.2007.07.004

35. Grace SL, Abbey SE, Kapral MK, Fang J, Nolan RP, Stewart $D E$. Effect of depression on five-year mortality after an acute coronary syndrome. Am J Cardiol. 2005 Nov 1;96(9):1179-85. doi: 10.1016/j.amjcard.2005.06.052. Epub 2005 Sep 1. PMID: 16253578.

36. de Jonge $\mathrm{P}$, van den Brink RH, Spijkerman TA, Ormel J. Only incident depressive episodes after myocardial infarction are associated with new cardiovascular events. J Am Coll Cardiol. 2006 Dec 5;48(11):2204-8. doi: 10.1016/j.jacc.2006.06.077. Epub 2006 Nov 9. PMID:17161246.

37. Meijer A, Conradi HJ, Bos EH, Thombs BD, van Melle JP, de Jonge P. Prognostic association of depression following myocardial infarction with mortality and cardiovascular events: a meta-analysis of 25 years of research. Gen Hosp Psychiatry. $2011 \quad$ May-Jun;33(3):203-16. doi: 10.1016/j.genhosppsych.2011.02.007. Epub 2011 Mar 31. PMID: 21601716.

38. van Melle JP, de Jonge P, Spijkerman TA, Tijssen JG, Ormel $\mathrm{J}$, van Veldhuisen DJ, van den Brink RH, van den Berg MP. Prognostic association of depression following myocardial infarction with mortality and cardiovascular events: a metaanalysis. Psychosom Med. 2004 Nov-Dec;66(6):814-22. doi: 10.1097/01.psy.0000146294.82810.9c. PMID: 15564344.

39. Celano CM, Villegas AC, Albanese AM, Gaggin HK, Huffman JC. Depression and Anxiety in Heart Failure: A Review. Harv Rev Psychiatry. 2018;26(4):175-184. doi:10.1097/HRP.000000000000016 
Table 1- Mental health disorder among men and women

\begin{tabular}{|c|c|c|c|c|c|}
\hline \multirow{7}{*}{ Mental health } & & & Male & Female & Total \\
\hline & \multirow{2}{*}{ No } & Number & 46 & 54 & 100 \\
\hline & & Percentage & $60.5 \%$ & $51.9 \%$ & $55.6 \%$ \\
\hline & \multirow{2}{*}{ Yes } & Number & 30 & 50 & 80 \\
\hline & & Percentage & $39.5 \%$ & $48.1 \%$ & $44.4 \%$ \\
\hline & \multirow{2}{*}{ Total } & Number & 76 & 104 & 180 \\
\hline & & Percentage & 100 & 100 & 100 \\
\hline
\end{tabular}

Table 2- The correlation between the sleep disorder and mental disorder among the acute coronary syndrome patients

\begin{tabular}{|c|c|c|c|c|c|}
\hline \multirow{8}{*}{ Sleep disorder } & \multirow{4}{*}{ No } & & \multicolumn{2}{|c|}{ Mental disorder } & \multirow{2}{*}{ Total } \\
\hline & & & Yes & $\mathrm{NO}$ & \\
\hline & & Number & 16 & 54 & 70 \\
\hline & & Percentage & $22.9 \%$ & $77.1 \%$ & $100 \%$ \\
\hline & \multirow{2}{*}{ Yes } & Number & 19 & 1 & 20 \\
\hline & & Percentage & $95 \%$ & $5 \%$ & $100 \%$ \\
\hline & \multirow{2}{*}{ Total } & Number & 35 & 55 & 90 \\
\hline & & Percentage & $38.9 \%$ & $61.1 \%$ & $100 \%$ \\
\hline
\end{tabular}

Table 3- The correlation between the sleep disorder and mental disorder among the acute coronary syndrome patients Chi-Square Tests

\begin{tabular}{|c|c|c|c|c|c|}
\hline & Value & df & Asymp. Sig. (2-sided) & Exact Sig. (2-sided) & Exact Sig. (1-sided) \\
\hline Pearson Chi-Square & $19.492^{\mathrm{a}}$ & 1 & .000 & & \\
\hline Continuity Correction $^{\mathrm{b}}$ & 17.386 & 1 & .000 & & \\
\hline Likelihood Ratio & 21.916 & 1 & .000 & & \\
\hline Fisher's Exact Test & & & & .000 & .000 \\
\hline Linear-by-Linear Association & 19.275 & 1 & .000 & & \\
\hline $\mathrm{N}$ of Valid Cases ${ }^{\mathrm{b}}$ & 90 & & & & \\
\hline
\end{tabular}

Table 4- The correlation between the sleep disorder and mental disorder among the acute myocardial infarction patients

\begin{tabular}{|c|c|c|c|c|c|}
\hline & & & \multicolumn{2}{|c|}{ Mental disorder } & \multirow{2}{*}{ Total } \\
\hline & & & Yes & $\mathrm{NO}$ & \\
\hline \multirow{6}{*}{ Sleep disorder } & \multirow{2}{*}{ No } & Number & 25 & 43 & 68 \\
\hline & & Percentage & $36.8 \%$ & $63.2 \%$ & $100 \%$ \\
\hline & \multirow{2}{*}{ Yes } & Number & 20 & 2 & 22 \\
\hline & & Percentage & $90.9 \%$ & $9.1 \%$ & $100 \%$ \\
\hline & \multirow{2}{*}{ Total } & Number & 45 & 45 & 90 \\
\hline & & Percentage & $50 \%$ & $50 \%$ & $100 \%$ \\
\hline
\end{tabular}

Table 5- The correlation between the mental health and sleep disorder among acute myocardial infarction patients

Chi-Square Tests

\begin{tabular}{|l|l|l|l|l|l|}
\hline & Value & df & Asymp. Sig. (2-sided) & Exact Sig. (2-sided) & Exact Sig. (1-sided) \\
\hline Pearson Chi-Square & $19.492^{\mathrm{a}}$ & 1 & .000 & \\
\hline Continuity Correction ${ }^{\mathrm{b}}$ & 17.386 & 1 & .000 & \\
\hline Likelihood Ratio & 21.916 & 1 & .000 & & \\
\hline Fisher's Exact Test & & & .000 & \\
\hline Linear-by-Linear Association $^{\mathrm{N} \text { of Valid Cases }}{ }^{\mathrm{b}}$ & 19.275 & 1 & .000 & .000 \\
\hline
\end{tabular}

\begin{tabular}{|c|c|c|c|c|}
\hline & Somatic symptoms & Anxiety & Social dysfunction & Depression \\
\hline Frequency & 52 & 100 & 86 & 32 \\
\hline Percentage & $28.9 \%$ & $55.6 \%$ & $47.8 \%$ & $17.8 \%$ \\
\hline
\end{tabular}

